\title{
МАРКЕТИНГОВОЕ ИССЛЕДОВАНИЕ РЫНКА ГОРОДСКИХ ПАССАЖИРСКИХ ПЕРЕВОЗОК ТЕРРИТОРИАЛЬНОГО ОБРАЗОВАНИЯ (НА ПРИМЕРЕ ГОРОДА ОРЕНБУРГ)
}

\author{
(c) 2020 Калиева Ольга Михайловна \\ доктор экономических наук, доцент \\ заведующий кафедрой маркетинга и торгового дела \\ Оренбургский государственный университет, Россия, Оренбург \\ E-mail:kom34@rambler.ru \\ (c) 2020 Карелин Николай Владимирович \\ аспирант кафедры маркетинга и торгового дела \\ Оренбургский государственный университет, Россия, Оренбург \\ E-mail: karelin93@mail.ru
}

В представленном исследовании выявлено отношение потребителей к услугам, предоставляемых городским пассажирским транспортом территориальному образованию город Оренбург (Российская Федерация). Для оценки мнений потребителей об услугах городских пассажирских перевозок использован исследовательский опрос путем анкетирования. Установлено, что качество обслуживания, уровень безопасности, санитарное состояние транспортных средств, полнота и доступность информации о перевозчике являются наиболее слабыми местами городского общественного транспорта. Полученные результаты маркетингового исследования, связанные с текущей оценкой положения предоставляемых услуг городским пассажирским транспортом, дают возможность реализовать потенциальные перспективы на основании обоснованных выводов, универсальны, и рекомендованы к непосредственному внедрению.

Ключевые слова: маркетинговое исследование, услуги, городской пассажирский транспорт, потребности потребителя

В организации функционирования, жизнедеятельности городской среды любого территориального образования определяющей составляющей выступают городские пассажирские перевозки. Из совокупности поставленных социально-экономических задач перед территориальными органами управления в сложившихся условиях актуальной становится задача, связанная с преобразованием в качественно новое состояние общественного транспорта, характеризующееся высоким уровнем доступности в соответствии с социальными стандартами [1]. Решение данной задачи предполагает полное удовлетворение объема растущих потребностей потребителей в перевозках, обеспечение устойчивых связей между территориальными образованиями города и повышение ценовой доступности услуг городских пассажирских перевозок $[2,3]$.

Сложившаяся ситуация на сегодняшний день в территориальном образовании - город Оренбург, предопределила конкретизацию приоритетных задач городских пассажирских пе- ревозок, представленными территориальными органами управления в виде «Концепции развития общественного транспорта города Оренбурга» $[7,8,9]$. Предлагаемая концепция заключается в формировании стратегии развития городских пассажирских перевозок в экономических, социальных и экологических направлениях - города Оренбург. Ключевой посыл концепции направлен на создание необходимых условий в городе Оренбурге для устойчиво функционирующей и доступной для населения единой системы общественного транспорта на основе формирования на территории (в городе) рынка транспортных услуг, регулируемого в интересах общества, представленных на территории хозяйствующих субъектов [4,5].

Разработанное и проведенное анкетирование потенциальных потребителей по основным критериям оценки работы городских пассажирских перевозок (время ожидания, степень удовлетворенности нужд и потребностей, уровень цен, безопасность, скоростной режим, график и регулярность, санитарное состояние, полнота и 
доступность информации, отношение к инновациям) на конкретной территории,- в городе Оренбурге предполагает получение актуальной информации о потребителях, конкурентах, поставщиках, конъюнктуры рынка городских пассажирских перевозок со стороны спроса и предпочтений потенциальных потребителей, что обеспечит обоснованность пула городских пассажирских перевозок [6].

Поскольку потенциальными потребителями услуг городских пассажирских перевозок является население в возрастном диапазоне (7-80 лет), то анкетирование проводилось среди населения определенных возрастных категорий: 7-20 лет, 20-40 лет, 40-60 лет, 60 лет и более.

Объем выборки определен по таблице 1.

Объем генеральной совокупности (численность населения г. Оренбурга на 2018 год) составила 547 тыс. человек. Таким образом, исходя из расчетов, объем выборки составил 400 человек. Надежность данного исследования составляет $\sim 95 \%$, а ошибка расчетов не превышает $\sim 5 \%$. С целью выявления спектра нижеперечисленных проблем нами реализован интернет опрос жителей города Оренбурга. Респондентам предложено ответить на следующие вопросы:

1. Возрастная группа респондента;

2. Социальная принадлежность респондента;

3. Частота пользования общественным транспортом;

4. Предпочитаемые виды транспорта;

5. Время ожидания транспортного средства на остановке;

6. Степень удовлетворенности нужд и потребностей респондента общественным транспортом;

7. Уровень цен на проезд в общественном транспорте;

8. Отношение респондента к новым автобусам на газомоторном (экологическом) топливе;

9. Новые (приоритетные) услуги в городских пассажирских перевозках;

10. График и регулярность работы городских пассажирских перевозок;

11. Уровень скоростного режима городских пассажирских перевозок;

12. Уровень безопасности городских пассажирских перевозок;

13. Санитарное состояние салонов транспортных средств;

14. Полнота и доступность информации о перевозчике.

Вся полученная информация, по результатам анкетирования, о респондентах и их предпочтениях представлена в таблицах (2-15).

По данным результатов анкетирования (таблица 2) следует, что более половины респондентов среднего возраста - представители возрастных групп «20-40 лет» $(52,5 \%)$ и «40-60 лет» (34,7\%). Небольшими группами представлены респонденты «60 лет и более» $(9,5 \%)$ и «7-20 лет» (3,3\%).

Наибольшее количество респондентов относят себя к специалистам на производстве и работникам органов государственного или муниципального управления (67,7\%), далее следуют рабочие и служащие (8,3\%), студенты $(7,5 \%)$, пенсионеры (7,5\%), предприниматели и бизнесмены (7\%), безработные (2\%).

Чуть более половины опрошенных респондентов пользуются общественным транспортом ежедневно $(53,8 \%)$, очень редко $-21 \%$, раз в неделю - 20,2\% (таблица 4). Не пользуются общественным транспортом только 5\% опрошен-

Таблица 1. Зависимость объема выборки от величины генеральной совокупности

\begin{tabular}{|l|l|l|l|l|l|l|l|l|l|}
\hline $\begin{array}{l}\text { Величина генеральной } \\
\text { совокупности, тыс. чел. }\end{array}$ & 0,5 & 1 & 2 & 3 & 4 & 5 & 10 & 100 & $>100$ \\
\hline Объем выборки, чел. & 222 & 286 & 333 & 350 & 360 & 370 & 385 & 398 & 400 \\
\hline
\end{tabular}

Таблица 2. Распределение респондентов по возрастной группе

\begin{tabular}{|l|l|l|}
\hline \multicolumn{1}{|c|}{ Возрастная группа } & \multicolumn{1}{|c|}{ Количество человек } & \multicolumn{1}{c|}{ \% соотношение } \\
\hline $7-20$ лет & 13 & 3,3 \\
\hline $20-40$ лет & 210 & 52,5 \\
\hline $40-60$ лет & 139 & 34,7 \\
\hline 60 лет и более & 38 & 9,5 \\
\hline
\end{tabular}


Таблица 3. Распределение респондентов по социальной принадлежности

\begin{tabular}{|l|l|l|}
\hline \multicolumn{1}{|c|}{ Социальная категория } & \multicolumn{1}{|c|}{ Количество человек } & \multicolumn{1}{|c|}{ \% соотношение } \\
\hline Рабочий, служащий (без высшего образования) & 33 & 8,3 \\
\hline $\begin{array}{l}\text { Специалист на производстве, работник органов государ- } \\
\text { ственного или муниципального управления (с высшим } \\
\text { образованием) }\end{array}$ & 271 & 67,7 \\
\hline предприниматель, бизнесмен & 28 & 7 \\
\hline учащийся, студент & 30 & 7,5 \\
\hline пенсионер & 30 & 7,5 \\
\hline безработный & 8 & 2 \\
\hline
\end{tabular}

Таблица 4. Частота пользования общественным транспортом

\begin{tabular}{|l|l|l|}
\hline \multicolumn{1}{|c|}{ Частота пользования (баллы) } & \multicolumn{1}{|c|}{ Количество человек } & \multicolumn{1}{c|}{ \% соотношение } \\
\hline Ежедневно (4) & 215 & 53,8 \\
\hline раз в неделю (3) & 81 & 20,2 \\
\hline очень редко (2) & 84 & 21 \\
\hline не пользуются совсем (1) & 20 & 5 \\
\hline
\end{tabular}

ных респондентов. Средний балл - 3,2 (частота пользования общественным транспортом чуть более раза в неделю).

Наибольшее количество респондентов предпочитает пользоваться личным автомобилем (46,7\%), общественным транспортом - 41,8\%, такси - 7,3\%, велосипедом или мотоциклом $4,2 \%$ (таблица 5).

Более половины респондентов ожидают свое транспортное средство на остановке в среднем от 5 до 15 минут (57,3\%), менее 5 минут $-33,5 \%$, $15-30$ минут $-5,2 \%$, более 30 минут $-4 \%$ (таблица 6). Средний балл $-3,2$ (среднее время ожидания транспортного средства составляет чуть менее 5-15 минут).

Более половины респондентов оценива- ют собственную удовлетворенность нужд и потребностей общественным транспортом как “удовлетворительно" (51,5\%). Оценку “хорошо" поставили 36,3\% респондентов, «неудовлетворительно» - 7,5\%, «отлично» $-4,7 \%$ (таблица 7 ). Средний балл $-2,4$ (степень удовлетворенности нужд и потребностей респондентов общественным транспортом оценено в большей степени как «удовлетворительно»).

Более половины респондентов считают приемлемыми цены на проезд (57,5\%), дорогими $-35 \%$, недорогими - 6,2\%, дешевыми $-0,8 \%$ (таблица 8). Средний балл - 3,3 (уровень цен за проезд в общественном транспорте оценены в большей степени как приемлемые).

Чуть более половины респондентов отно-

Таблица 5. Предпочитаемые виды транспорта

\begin{tabular}{|l|l|l|}
\hline \multicolumn{1}{|c|}{ Вид транспорта } & \multicolumn{1}{|c|}{ Количество человек } & \multicolumn{1}{c|}{ \% соотношение } \\
\hline общественный & 167 & 41,8 \\
\hline личный автомобиль & 187 & 46,7 \\
\hline такси & 29 & 7,3 \\
\hline велосипед/мотоцикл & 17 & 4,2 \\
\hline
\end{tabular}

Таблица 6. Время ожидания транспортного средства на остановке

\begin{tabular}{|l|l|l|}
\hline \multicolumn{1}{|c|}{ Время ожидания (баллы) } & \multicolumn{1}{|c|}{ Количество человек } & \multicolumn{1}{c|}{ \% соотношение } \\
\hline менее 5 минут (4) & 134 & 33,5 \\
\hline 5-15 минут (3) & 229 & 57,3 \\
\hline $15-30$ минут (2) & 21 & 5,2 \\
\hline более 30 минут (1) & 16 & 4 \\
\hline
\end{tabular}


Таблица 7. Степень удовлетворенности нужд и потребностей респондента общественным транспортом

\begin{tabular}{|l|l|l|}
\hline \multicolumn{1}{|c|}{ Оценка (баллы) } & \multicolumn{1}{|c|}{ Количество человек } & \multicolumn{1}{c|}{ \% соотношение } \\
\hline Отлично (4) & 19 & 4,7 \\
\hline Хорошо (3) & 145 & 36,3 \\
\hline Удовлетворительно (2) & 206 & 51,5 \\
\hline Неудовлетворительно (1) & 30 & 7,5 \\
\hline
\end{tabular}

сятся положительно к новым автобусам на газомоторном (экологическом) топливе (52\%), нейтрально - 46,7\%, против - 1,3\%. (таблица 9). Средний балл - 2,5 (отношение большинства респондентов к новым автобусам на газомоторном топливе колеблется между положительным и нейтральным).

Наибольшее количество респондентов предпочитают внедрение автоинформатора в общественном транспорте (33,5\%), 29\% респондентов предпочли внедрение мобильного приложения, 22,3\% - скидку на проезд по транспортной карте, 9,5\% - «счастливый» билет, 5,7\% - наличие в салоне транспортного средства книги жалоб и предложений (таблица 10).

Наибольшее количество респондентов оценило график и регулярность работы общественного транспорта на «4» (39,2\%), 31,8\% респондентов поставило оценку «3», 16,5\% - на «5», 6,25\% - на «2», 6,25\% - на «1» (таблица 11).
Средний балл - 3,5 (общая оценка графика и регулярности работы городских пассажирских перевозок колеблется между «нейтрален» и «доволен»).

Наибольшее количество респондентов оценило скоростной режим общественного транспорта на «4» (40\%), 29,8\% респондентов оценило на «3», 15,7\% - на «5», 7,5\% - на «2», $7 \%$ - на «1» (таблица 12). Средний балл - 3,5 (общая оценка колеблется между «нейтрален» и «доволен»).

Наибольшее количество респондентов (32,5\%) нейтрально оценило уровень безопасности общественного транспорта, 30,7\% респондентов остались довольны, 15,5\% - недовольны, $11,5 \%$ - очень довольны, 9,8\% - очень недовольны (таблица 13). Средний балл - 3,2 (общая оценка уровня безопасности городских пассажирских перевозок в большей степени «нейтрален»).

Таблица 8. Оценка уровня цен за проезд в общественном транспорте

\begin{tabular}{|l|l|l|}
\hline \multicolumn{1}{|c|}{ Оценка (баллы) } & \multicolumn{1}{|c|}{ Количество человек } & \multicolumn{1}{c|}{ \% соотношение } \\
\hline Дорого (4) & 142 & 35,5 \\
\hline Приемлемо (3) & 230 & 57,5 \\
\hline Недорого (2) & 25 & 6,2 \\
\hline Дешево (1) & 3 & 0,8 \\
\hline
\end{tabular}

Таблица 9. Отношение респондентов к новым автобусам на газомоторном (экологическом) топливе

\begin{tabular}{|l|l|l|}
\hline \multicolumn{1}{|c|}{ Оценка (баллы) } & \multicolumn{1}{|c|}{ Количество человек } & \multicolumn{1}{c|}{ \% соотношение } \\
\hline Положительно (3) & 208 & 52 \\
\hline Нейтрально (2) & 187 & 46,7 \\
\hline Против (1) & 5 & 1,3 \\
\hline
\end{tabular}

Таблица 10. Новые (приоритетные) услуги в городских пассажирских перевозках

\begin{tabular}{|l|l|l|}
\hline \multicolumn{1}{|c|}{ Новая услуга } & \multicolumn{1}{|c|}{ Количество человек } & \multicolumn{1}{c|}{ \% соотношение } \\
\hline автоинформатор & 134 & 33,5 \\
\hline «счастливый» билет & 38 & 9,5 \\
\hline мобильное приложение & 116 & 29 \\
\hline скидка на проезд по транспортной карте & 89 & 22,3 \\
\hline $\begin{array}{l}\text { наличие в салоне транспортного средства } \\
\text { книги жалоб и предложений }\end{array}$ & 23 & 5,7 \\
\hline
\end{tabular}


Таблица 11. Оценка графика и регулярности работы городских пассажирских перевозок

\begin{tabular}{|l|l|l|}
\hline \multicolumn{1}{|c|}{ Оценка (баллы) } & \multicolumn{1}{c|}{ Количество человек } & \multicolumn{1}{c|}{ \% соотношение } \\
\hline 1 (очень недоволен) & 25 & 6,25 \\
\hline 2 (недоволен) & 25 & 6,25 \\
\hline 3 (нейтрален) & 127 & 31,8 \\
\hline 4 (доволен) & 157 & 39,2 \\
\hline 5 (очень доволен) & 66 & 16,5 \\
\hline
\end{tabular}

Таблица 12. Оценка скоростного режима городских пассажирских перевозок

\begin{tabular}{|l|l|l|}
\hline \multicolumn{1}{|c|}{ Оценка (баллы) } & \multicolumn{1}{|c|}{ Количество человек } & \multicolumn{1}{c|}{ \% соотношение } \\
\hline 1 (очень недоволен) & 28 & 7 \\
\hline 2 (недоволен) & 30 & 7,5 \\
\hline 3 (нейтрален) & 119 & 29,8 \\
\hline 4 (доволен) & 160 & 40 \\
\hline 5 (очень доволен) & 63 & 15,7 \\
\hline
\end{tabular}

Наибольшее количество респондентов (36,7\%) нейтрально оценило санитарное состояние салонов общественного транспорта, $34,2 \%$ респондентов остались довольны, 16,5\% - недовольны, 6,3\% - очень недовольны, 6,3\% - очень недовольны (таблица 14). Средний балл $-3,2$ (общая оценка санитарного состояния салонов транспортных средств в большей степени «нейтрален»).

Наибольшее количество респондентов (36,8\%) остались довольны полнотой и доступностью информации о перевозчике, $29 \%$ респондентов остались нейтральны, 15,2\% - очень довольны, $14,5 \%$ - недовольны, 4,5\% - очень недовольны (таблица 15). Средний балл $-3,4$ (общая оценка полноты и доступности инфор- мации о перевозчике в большей степени «нейтрален»).

Резюмируя, отметим, что в результате проведенного маркетингового исследования потребители услуг городских пассажирских перевозок в возрастном диапазоне от 20 до 60 лет в большей степени склонны отдавать предпочтение индивидуальному транспорту (55,7\%), несмотря на то, что индивидуальный транспорт наиболее затратный (10,3\% против 3\% доли средних расходов населения в России (по данным источника Euromonitor)). Данное обстоятельство связано с выявленными негативно влияющими критериями на выбор предоставляемых услуг городского пассажирского транспорта исследуемого территориального образования (город Оренбург)

Таблица 13. Оценка уровня безопасности городских пассажирских перевозок

\begin{tabular}{|l|l|l|}
\hline \multicolumn{1}{|c|}{ Оценка (баллы) } & \multicolumn{1}{|c|}{ Количество человек } & \multicolumn{1}{c|}{ \% соотношение } \\
\hline 1 (очень недоволен) & $39 \quad 9,8$ \\
\hline 2 (недоволен) & 62 & 15,5 \\
\hline 3 (нейтрален) & 130 & 32,5 \\
\hline 4 (доволен) & 123 & 30,7 \\
\hline 5 (очень доволен) & 46 & 11,5 \\
\hline
\end{tabular}

Таблица 14. Оценка санитарного состояния салонов транспортных средств

\begin{tabular}{|l|l|l|}
\hline \multicolumn{1}{|c|}{ Оценка (баллы) } & \multicolumn{1}{c|}{ Количество человек } & \multicolumn{1}{c|}{ \% соотношение } \\
\hline 1 (очень недоволен) & 25 & 6,3 \\
\hline 2 (недоволен) & 66 & 16,5 \\
\hline 3 (нейтрален) & 147 & 36,7 \\
\hline 4 (доволен) & 137 & 34,2 \\
\hline 5 (очень доволен) & 25 & 6,3 \\
\hline
\end{tabular}


Таблица 15. Оценка полноты и доступности информации о перевозчике

\begin{tabular}{|l|l|l|}
\hline \multicolumn{1}{|c|}{ Оценка (баллы) } & \multicolumn{1}{c|}{ Количество человек } & \multicolumn{1}{c|}{ \% соотношение } \\
\hline 1 (очень недоволен) & 18 & 4,5 \\
\hline 2 (недоволен) & 58 & 14,5 \\
\hline 3 (нейтрален) & 116 & 29 \\
\hline 4 (доволен) & 147 & 36,8 \\
\hline 5 (очень доволен) & 61 & 15,2 \\
\hline
\end{tabular}

такими как: степень удовлетворенности нужд и потребностей респондента общественным транспортом (2,4 балла из 4), уровень безопасности (3,2 балла из 5), санитарное состояние транспортных средств (3,2 балла из 5), полнота и доступность информации о перевозчике $(3,4$ балла из 5). Комплексное и последовательное устранение указанных негативных критериев позволит устойчиво функционировать рынку городских пассажирских перевозок исследуемого территориального образования.

\section{Библиографический список}

1. Шугрина Е.С. Может ли муниципальный контроль обеспечить безопасность городской среды: реформа и контрольно-надзорной деятельности и судебная практика // Правоприменение. 2019. № 1(3). С.86-99.

2. Калмыков М.Ю., Малышев Н.В. Перспективные технологии пассажирских перевозок в условиях урбанизации // Бюллетень результатов научных исследований. 2019. Вып. 3. С. 5-12.

3. Иванова И.Ю. Современное состояние и пути развития пассажирских перевозок в городе Красноярске // Актуальные проблемы авиации и космонавтики. 2016. Том 2. С.988-990.

4. Якунин Н.Н., Шмарин А.А., Шмарин А.П. Моделирование экономической мотивации качественных перевозок пассажиров автомобильным транспортом по городским регулярным маршрутам // Проблемы современной экономики. 2017. С. 198-201.

5. Шмарин А. А. Об особенностях формирования доходов и расходов транспортной организаций, осуществляющих пассажирские перевозки // Экономика и бизнес: теория и практика. 2018.

6. Дрючин Д.А., Майоров М.А. Основные направления повышения качествв транспортного обслуживания населения городским пассажирским транспортом по регулярным маршрутам // Вестник Оренбургского государственного университета. 2015. № 4(179). С. 30-36.

7. Оренбургский городской совет. Решение от 18 сентября 2012 года № 475 «О концепции развития общественного транспорта города Оренбурга» [Электронный ресурс]. URL: http://www.orenburg.ru/general_ news/320/11502/ (дата обращения: 15.03.2020).

8. Статья 12, 132 Конституции Российской Федерации [Электронный ресурс]. URL: http://constitutionrf.ru/ rzd-1/gl-8/st-132-krf (дата обращения: 15.03.2020).

9. Статья 35 Федерального закона от 06.10.2003 N 131-Ф3 «Об общих принципах организации местного самоуправления в Российской Федерации» [Электронный ресурс]. URL: http://www.consultant.ru/document/ cons_doc_LAW_44571/ (дата обращения: 15.03.2020).

10. Официальный сайт «Города России» [Электронный ресурс]. URL: города-россия.рф (дата обращения: 12.10.2018). 